\title{
Plant-based synthesis of silver nanoparticles in Handelia trichophylla and their biological activities
}

\author{
MOHAMMAD EHSAN TAGHAVIZADEH YAZDI ${ }^{1}$, MOHAMMAD SADEGH AMIRI ${ }^{2}$, \\ HASAN ALI HOSSEINI ${ }^{3}$, REZA KAZEMI OSKUEE ${ }^{4}$, HASAN MOSAWEE ${ }^{5}$, \\ KIMIYA PAKRAVANAN ${ }^{6}$ and MAJID DARROUDI ${ }^{7,8, * \mathbb{D}}$ \\ ${ }^{1}$ NanoBioelectrochemistry Research Center, Bam University of Medical Sciences, Bam, Iran \\ ${ }^{2}$ Department of Biology, Payame Noor University, Tehran, Iran \\ ${ }^{3}$ Chemistry Department, Payame Noor University, Tehran 19395-4697, Iran \\ ${ }^{4}$ Targeted Drug Delivery Research Center, Mashhad University of Medical Sciences, Mashhad, Iran \\ ${ }^{5}$ Department of Biology, Mashhad Branch, Islamic Azad University, Mashhad, Iran \\ ${ }^{6}$ Neurogenic Inflammation Research Center, Mashhad University of Medical Sciences, Mashhad 9177948564, Iran \\ ${ }^{7}$ Nuclear Medicine Research Center, Mashhad University of Medical Sciences, Mashhad, Iran \\ ${ }^{8}$ Department of Modern Sciences and Technologies, Faculty of Medicine, Mashhad University of Medical Sciences, \\ Mashhad, Iran \\ *Author for correspondence (darroudim@mums.ac.ir; majiddarroudi@gmail.com)
}

MS received 25 September 2018; accepted 23 January 2019; published online 13 May 2019

\begin{abstract}
In this research, silver nanoparticles (AgNPs) were prepared via a 'green' procedure using an aqueous extract of Handelia trichophylla. The formation of AgNPs was confirmed by its light brown colour. The AgNPs were formed in silver nitrate $(1 \mathrm{mM})$ via a bioreduction process in spherically shaped NPs with a mean diameter in the range of 20-50 nm. Moreover, the green synthesized AgNPs seemed to demonstrate a higher antibacterial activity against human pathogenic bacteria. In addition, the in vitro cytotoxicity effect of biosynthesized AgNPs was also investigated, which was detected to be up to $15.62 \mu \mathrm{g} \mathrm{ml}^{-1}$ in the treated Neuro2A cells. Low toxicity and high antibacterial activity of biosynthesized silver nanoparticles can be utilized in different biological, biomedical and industrial applications.
\end{abstract}

Keywords. Silver nanoparticles; biosynthesis; Handelia trichophylla; antibacterial; cytotoxicity.

\section{Introduction}

In the past decade, many studies on metal nanoparticles $(\mathrm{Ag}$, $\mathrm{Au}, \mathrm{Pt}, \mathrm{Pd}$, etc.) have been developed due to their unique chemical (e.g., biosensor), physical (e.g., electrical), biological (antimicrobial and anti-tumour) and other different properties, which have shown their completely dissimilar characteristics from their bulk structures [1-6]. AgNPs stand as one of the most vital metal NPs that are employed in various applications including photonics [7], catalytic [8], bio-sensing [9], antibacterial [10], antifungal [11], water purification [12], textiles [13] and wound treatments [14]. In order to prepare metal NPs, different chemical processes and physical techniques have been developed such as wet-chemical [15], sono-chemical [16], light-irradiation [17], microwave irradiation [18], $\gamma$-irradiation [19], laser ablation [20], etc.

On the other hand, in preparing different nanostructures, plant extracts have attracted the notice of many in the past years for being facile, available, cost-effective, ecologically friendly and having low toxicity [21-28]. Handelia trichophylla, coming from the Asteraceae family, is an IranoTuranian species with a distribution range that goes across
Iran (in the western zone) all the way to China (in the eastern zone). It is a plant that is usually employed in the treatment of respiratory illnesses, skin problems, kidney stones and as an anti-haemorrhage by the people in north-eastern Iran [29,30]. In this research, we conducted a procedure that is quite unique in its own way regarding the formation of AgNPs, which is a biological method that utilizes an aqueous extract of Handelia trichophylla at normal physical and chemical conditions. In addition, the antibacterial activities of AgNPs were studied.

\section{Experimental}

\subsection{Synthesis of AgNPs}

The aerial full flowering parts of Handelia trichophylla (Schrenk) Heimerl were collected from the region of Zangelanlo (Khorasan Razavi province, Iran) and were washed with deionized water several times. Then, $3.0 \mathrm{~g}$ of homogeneous shoots were separated into tiny sections, while later on they were soaked in $100 \mathrm{ml}$ of deionized water. The mentioned shoots were continuously stirred at room temperature 

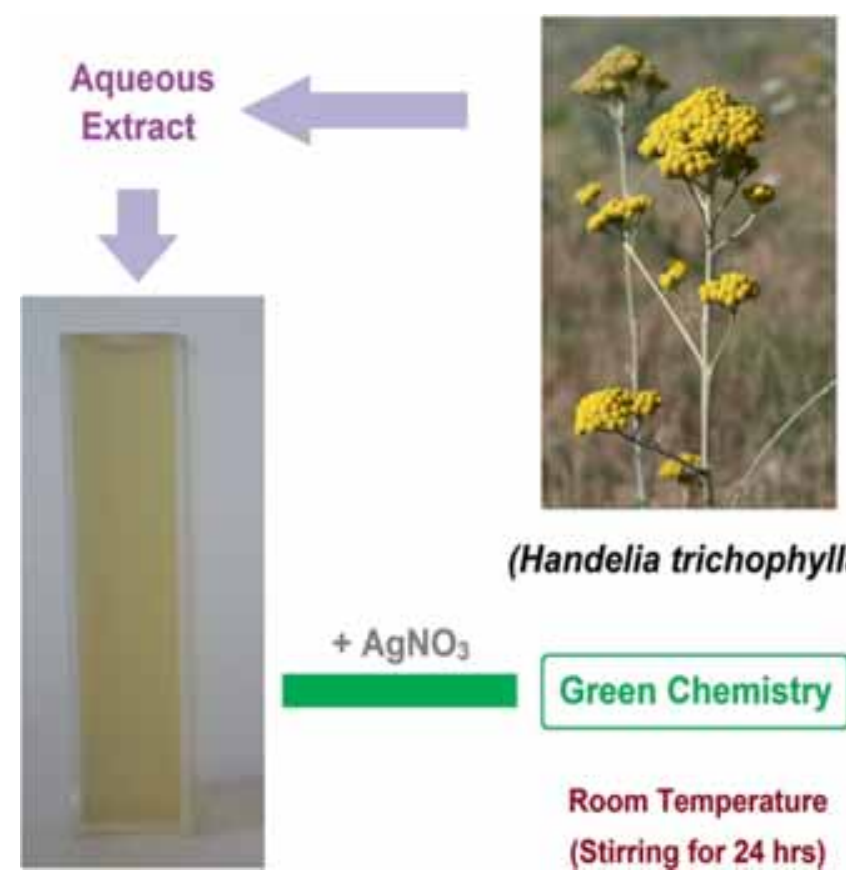

(Handelia trichophylla)

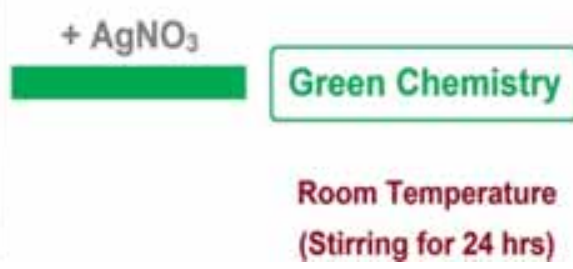

\section{Bio-Synthesized Silver Nanoparticles}

Figure 1. A plan of AgNP formation in the Handelia trichophylla aqueous extract.

for a duration of $24 \mathrm{~h}$. In addition, they were filtered for the purpose of extraction. Next, the resulting extract was kept at a temperature of $4^{\circ} \mathrm{C}$ to be utilized in the future. Then, $5 \mathrm{ml}$ of the shoot extract was appended carefully, drop by drop, to the silver nitrate aqueous solution $(1 \mathrm{mM})$. The obtained solution was stirred for $12 \mathrm{~h}$ to acquire colloids. The schematic diagram regarding the production of AgNPs is shown in figure 1.

\subsection{Characterization tests}

The biosynthesized colloidal AgNPs were characterized through several laboratory equipment including UV-Vis spectrophotometry, field emission scanning electron microscopy (FESEM)/energy dispersive X-ray (EDX), transmission electron microscopy (TEM), Fourier-transform infrared spectroscopy (FTIR) and X-ray powder diffraction (XRD).

\subsection{Antibacterial assay}

The disk diffusion method was applied to evaluate the antibacterial examination of AgNPs against Gram positive (i.e., S. aureus and B. subtilis) and Gram negative (i.e., E. coli and $P$. aeruginosa) [31] bacteria. Shoot extract was used as a control group. Gentamicin and streptomycin were utilized as standards in the treatment of pathogens. Zones of inhibition were calculated and are demonstrated in table 1. It is worth mentioning that all of the antibacterial tests were performed in triplicates.
Table 1. Inhibition zones of Handelia trichophylla-mediated AgNPs, controls and standards.

\begin{tabular}{|c|c|c|c|c|}
\hline \multirow[b]{3}{*}{ Bacteria } & \multicolumn{4}{|c|}{ Inhibition zones (mm) } \\
\hline & \multirow{2}{*}{$\frac{\text { Test }}{\text { AgNPs }}$} & \multirow{2}{*}{$\frac{\text { Negative control }}{\text { Control }}$} & \multicolumn{2}{|c|}{ Positive control } \\
\hline & & & S & GM \\
\hline E. coli & 9.1 & NA & 11.3 & 15.0 \\
\hline P. aeruginosa & 8.5 & NA & 9.8 & 15.1 \\
\hline B. subtilis & 8.2 & NA & 11.3 & 19.2 \\
\hline S. aureus & 10.2 & NA & 16.3 & 26.0 \\
\hline
\end{tabular}

NA, not appearing; GM, gentamicin; S, streptomycin.

\subsection{Cell culture}

A Neuro2A cell line was obtained from the Cell Bank of Central Laboratory in Mashhad University of Medical Sciences. These particular cells were developed in Dulbecco's modified Eagle's medium that contained $10 \%$ fetal bovine serum. The used medium was adjusted to comprise $1 \%$ penicillinstreptomycin $\left(50 \mu \mathrm{g} \mathrm{ml}^{-1}\right.$, PAN-Biotech) and l-glutamine (2 mM, PAN-Biotech). All of the cells were maintained at a temperature of $37^{\circ} \mathrm{C}$, with $5 \% \mathrm{CO}_{2}$ and $95 \%$ air, and also with $100 \%$ relative humidity.

Subsequent to $48 \mathrm{~h}$ of incubation, the Neuro2A cells were harvested by trypsinization for a duration of $3 \mathrm{~min}$ and were cleansed with phosphate-buffered saline (PBS). Then, they were re-suspended in $2 \mathrm{ml}$ of PBS while being centrifuged 
(at a speed of $1200 \mathrm{rpm}$ for $8 \mathrm{~min}$ ). The cells were counted and distributed in flat-bottomed 96-multiwell ELISA plates, while maintaining a plating density of 10,000 cells per well. The plates were incubated for a period of $24 \mathrm{~h}$ at a temperature of $37^{\circ} \mathrm{C}$ in an atmosphere containing $5 \% \mathrm{CO}_{2}$, so that the cells would get attached to the bottom of the wells.

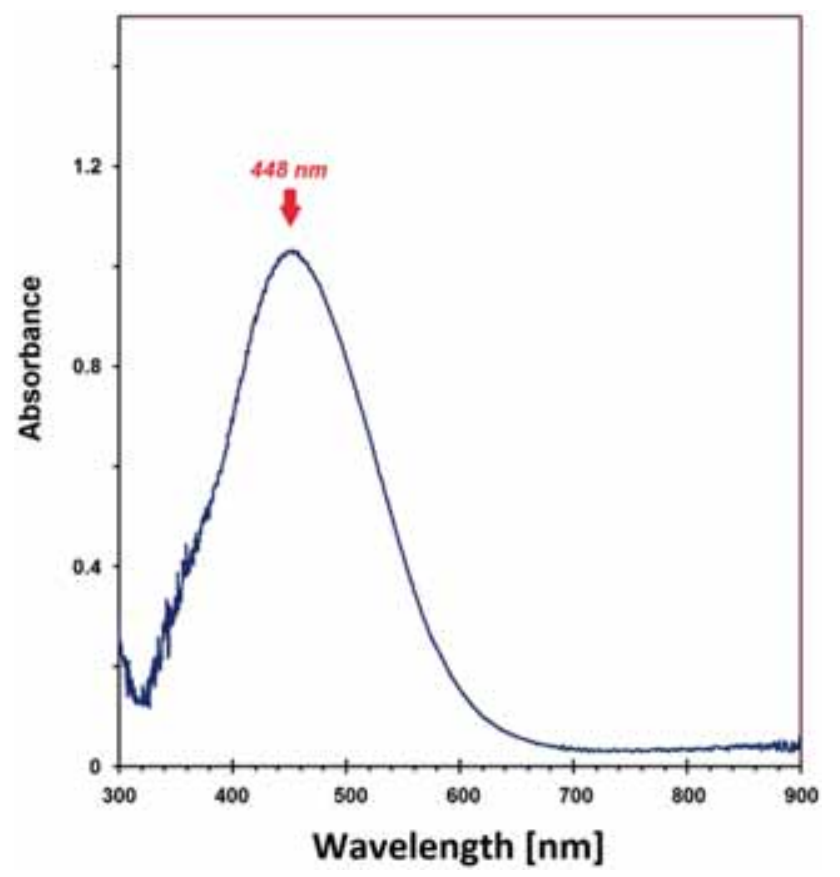

Figure 2. The UV-Vis spectrophotometry analysis of AgNPs in the Handelia trichophylla shoot extract.

\subsection{3-(4,5-Dimethylthiazol-2-yl)-2,5-diphenyltetrazolium bromide (MTT) assay}

The cellular toxicity of the AgNPs was investigated through the employment of a MTT assay as a sensitive and quantitative colorimetric evaluation test to observe and measure the activity of enzymes. In brief, Neuro2A cells were seeded at a density of 10,000 cells per well in a 96 -well plate $(100 \mu 1$ per well). Then, the plates were located in an incubator at $37^{\circ} \mathrm{C}$ for $24 \mathrm{~h}$. Different concentrations (e.g., 0, 0.49, 0.98, 1.95, $3.90,7.80,15.62,31.25,62.50,125$ and $250 \mu \mathrm{g} \mathrm{ml}^{-1}$ ) of colloidal AgNPs were inoculated into grown cells that contained $100 \mu 1$ of medium, while triplicates were added to the wells. This procedure was also repeated in triplicates.

During this period, after each day of incubation, $20 \mu 1$ of $5 \mathrm{mg} \mathrm{ml}^{-1}$ MTT dissolved in PBS was added to each well. At the end of incubation, the media were discarded and formazan crystals which were shaped by MTT metabolism were liquefied and dissolved through the inclusion of $100 \mu \mathrm{l}$ of DMSO. Then, the plates were slowly shaken in a shaker for $5 \mathrm{~min}$ and then the optical absorbance was measured at $590 \mathrm{~nm}$ by the use of a microplate reader (Statfax-2100, Awareness Technology, USA). The cell viability (\%) that is associated with the control wells, which comprised the cell culture medium, was obtained through the following equation:

$$
\frac{[A]_{\text {test }}}{[A]_{\text {control }}} \times 100,
$$

where $[A]_{\text {test }}$ stands as the sample absorbance and $[A]_{\text {control }}$ is the control absorbance. The values of metabolic activity were gathered in the form of mean $\pm \mathrm{SD}$ of triplicates.

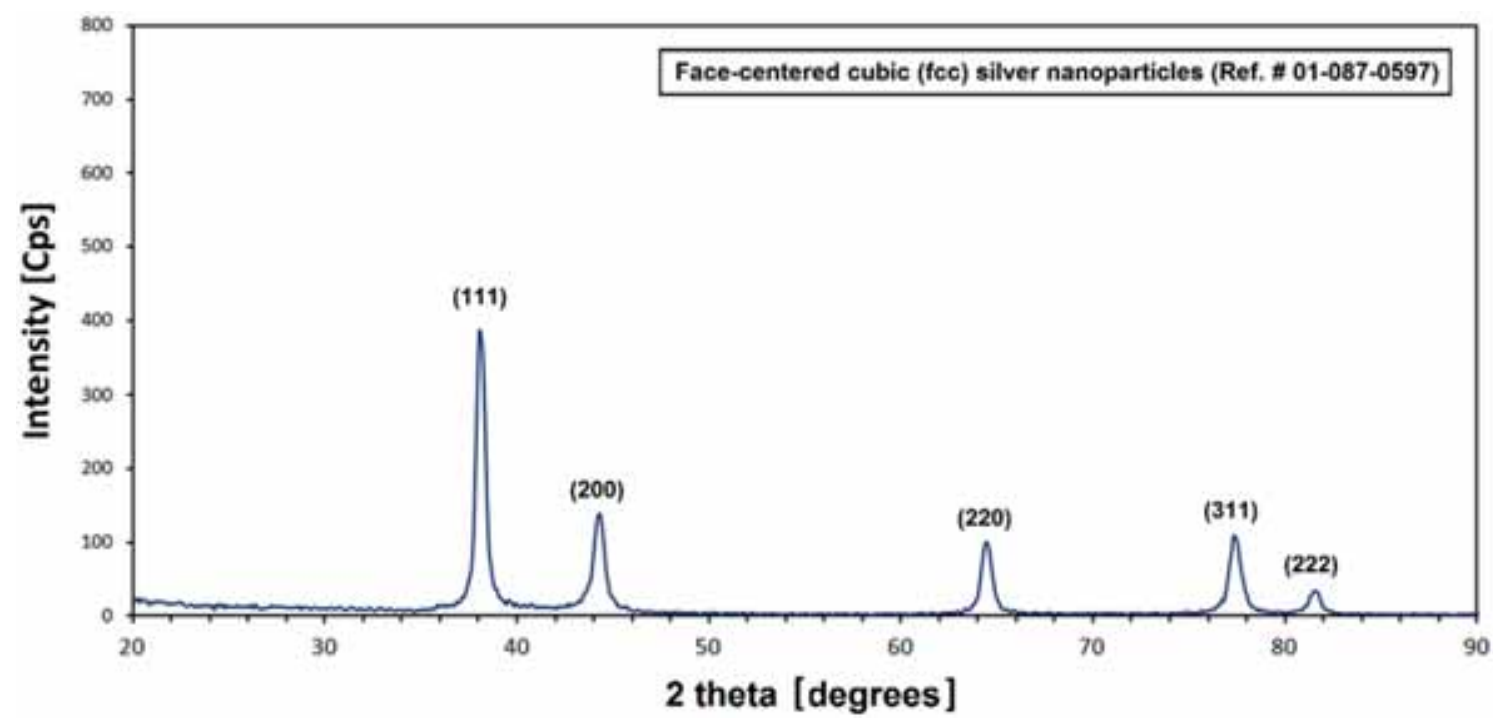

Figure 3. The powder X-ray diffraction pattern of biosynthesized AgNPs. 


\section{Results and discussion}

\subsection{UV-Vis spectrophotometry}

The resulting dark brown colour of the reaction mixture may have been caused by the collective oscillation generated by electrons on the surface of the created AgNPs, which is famous as the surface plasmon resonance (SPR) [32-34] phenomenon. By adding shoot extract after enduring the reaction period of $12 \mathrm{~h}$, the initial colour of $\mathrm{AgNO}_{3}$ turned to orange. The inducement of this particular colour change in the reaction solution suggests that the changing of $\mathrm{Ag}^{+}$to $\mathrm{Ag}^{0}$ has happened. As is clearly demonstrated in figure 2, the resultant AgNPs had a characteristic SPR band (achieved by a

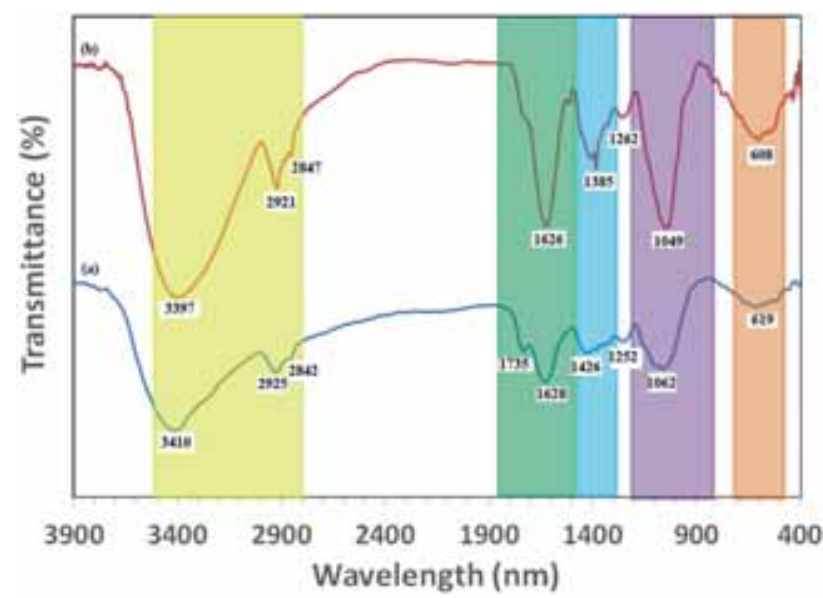

Figure 4. The FTIR spectra of biosynthesized (a) AgNPs and (b) Handelia trichophylla shoot extract.

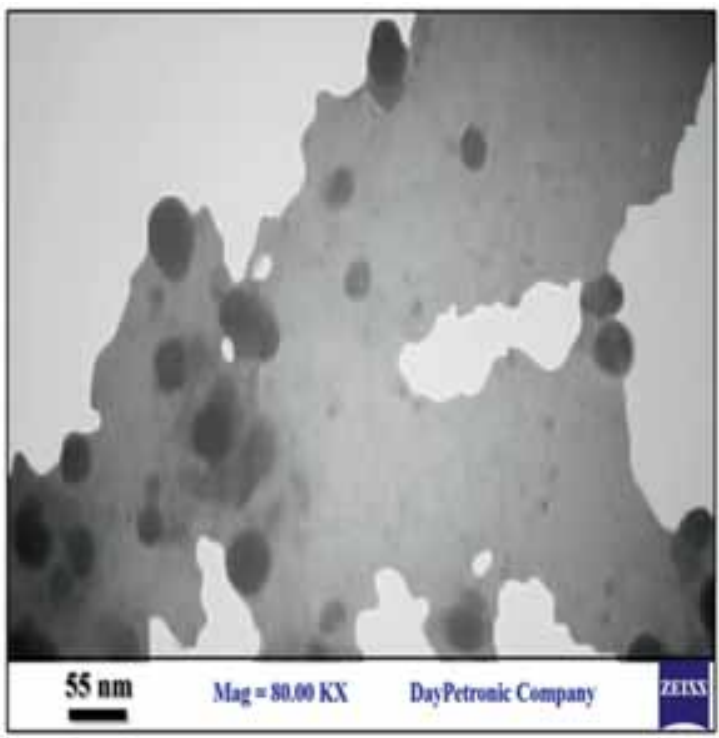

UV-Vis spectrophotometer; CECIL instrument CE 9500, $\mathrm{UK}$ ) at $448 \mathrm{~nm}$ that could be attributed to the creation of homogenous spherical AgNPs [35]. The existence of sufficient bio-reductant molecules that performed the task of reducing within the shoot extracts caused great reduction in the $\mathrm{AgNO}_{3}$ solution as AgNPs.

\subsection{XRD analysis}

The XRD pattern of AgNPs was scanned with an XRD machine (D8 ADVANCE-BRUKER, Germany) in a range of $20-90^{\circ}(2 \theta)$, which is displayed in figure 3 . The XRD demonstrates the fcc (faced centred cubic) structure of AgNPs, considering that it comprises diffraction peaks at 38.1, 44.2, 64.2, 77.4 and $81.8^{\circ}$ in accordance with (111), (200), (220), (311) and (222) planes. The preferential orientation of AgNPs along the (111) plane is certified by the diffraction peak at $38^{\circ}$ that seemed to contain a robust diffraction intensity. The crystallite size (average) of AgNPs was also estimated via Scherrer's equation [36]:

$$
D=\frac{K \lambda}{\beta \cos \theta}
$$

In this equation, $D$ stands as the crystallite size, $\lambda$ is the wavelength of the applied X-ray (1.5406 $\AA$ ), $\beta$ is the full width at half maximum and $\theta$ is the Bragg's angle. The estimated crystallite size of AgNPs was found to be about $15.5 \mathrm{~nm}$.

\subsection{FTIR analysis}

FTIR measurements were conducted in an effort to identify the various chemical groups in biomolecules that seem to be

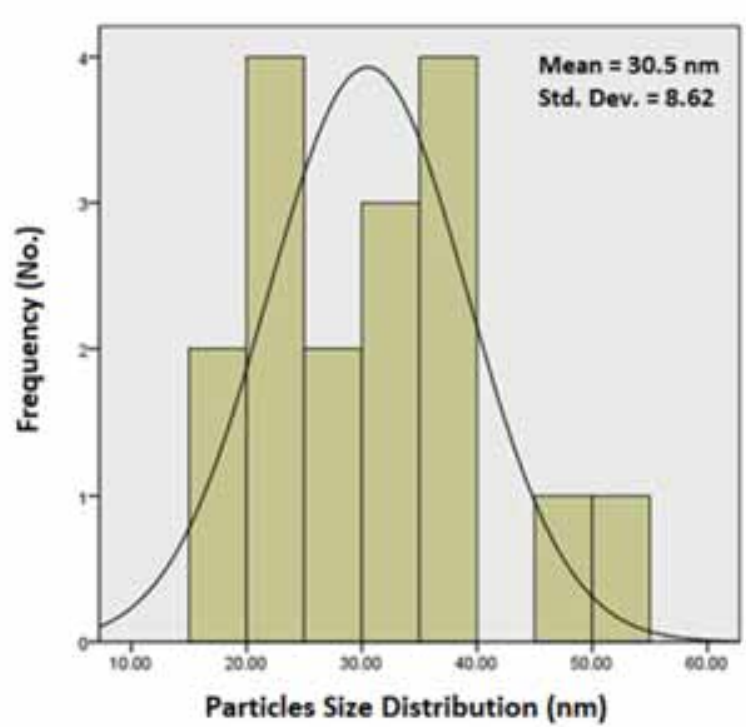

Figure 5. High magnification $(\times 80,000)$ TEM image of the biosynthesized AgNPs using the Handelia trichophylla shoot extract (left) and its corresponding particles size histogram (right). 


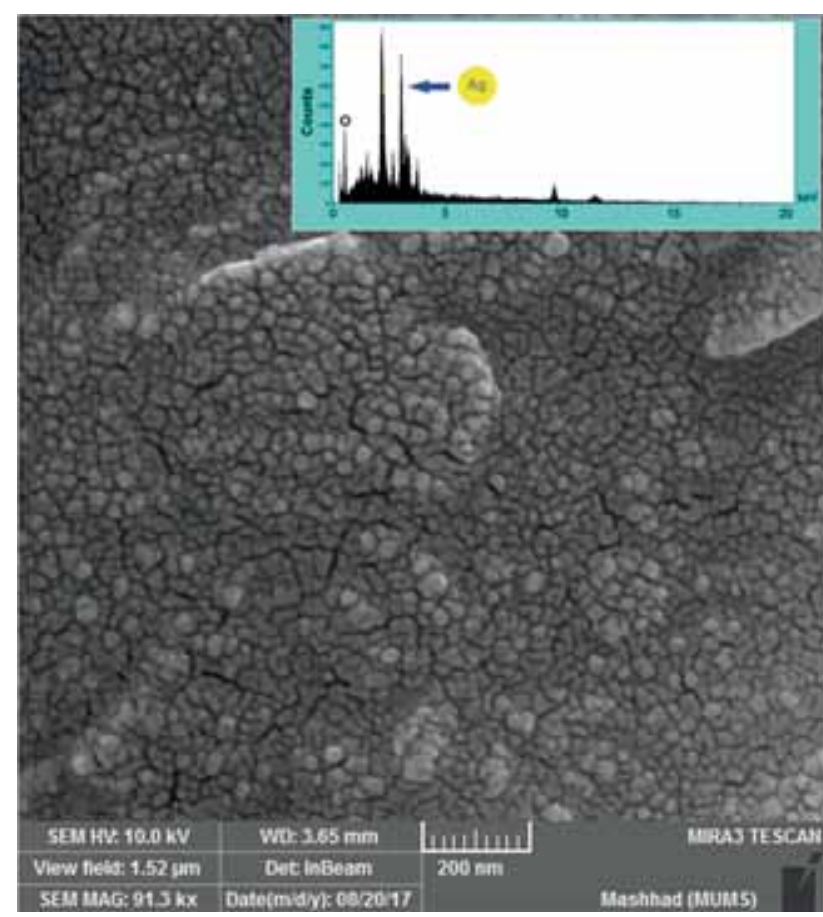

Figure 6. The FESEM image and EDX spectrum of the biosynthesized AgNPs using the Handelia trichophylla shoot extract. responsible for the bio-reduction of $\mathrm{Ag}^{+}$and capping as well as stabilizing the AgNPs. The FTIR spectrum illustrates particular absorption bands at 3397, 2921, 2847, 1626, 1520, $1385,1262,1049$ and $608 \mathrm{~cm}^{-1}$; this observation signifies the existence of the capping agent along the nanoparticles (figure 4). The detected bands that existed at $3397 \mathrm{~cm}^{-1}$ in the spectra correlate with the $\mathrm{O}-\mathrm{H}$ stretching vibration, which is induced due to the existence of alcohols and phenols. Also, the observed peaks in the regions 2921 and $2847 \mathrm{~cm}^{-1}$ are due to $v(\mathrm{C}-\mathrm{H})$ of aromatic compounds. In addition, the band at $1626 \mathrm{~cm}^{-1}$ in the spectra correlates with $\mathrm{C}-\mathrm{N}$ and $\mathrm{C}-\mathrm{C}$ stretching and indicates the presence of proteins. Moreover, the peak at $1385 \mathrm{~cm}^{-1}$ exemplifies the $\mathrm{N}-\mathrm{O}$ symmetry stretching, which represents the nitro compound. Furthermore, the band at $1262 \mathrm{~cm}^{-1}$ seems to match with $v(\mathrm{C}-\mathrm{N})$ that belongs to amines. Also, there is a possibility that the band in the region $608 \mathrm{~cm}^{-1}$ would correspond to $v(\mathrm{C}-\mathrm{Br})$ that seems to be one of the properties of alkyl halides. The mentioned functional groups contain significant responsibilities in the stability and/or capping of AgNPs, which have been announced in many research studies $[37,38]$. The peak at $1735 \mathrm{~cm}^{-1}$ which is absent for the AgNP FT-IR spectrum, is the bending vibration of the $\mathrm{C}-\mathrm{C}$ stretching and could be due to the stabilization of AgNPs through this group.

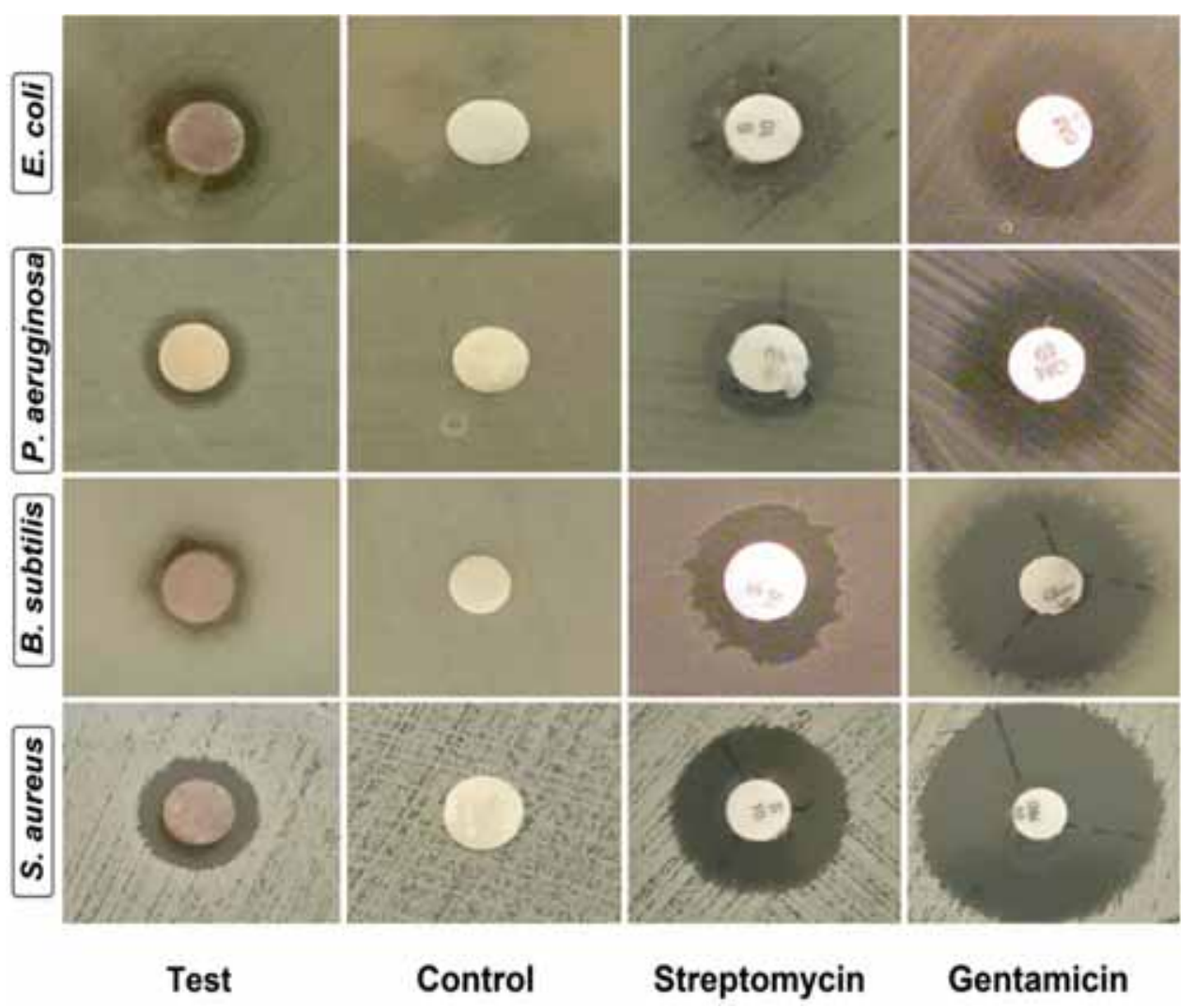

Figure 7. Antibacterial properties of Handelia trichophylla-mediated AgNPs against Gram-negative and Gram-positive bacteria. 


\subsection{Microscopic studies}

The TEM micrograph of AgNPs that were synthesized through the green method is displayed in figure 5. The captured TEM image achieved by the TEM machine (Zeiss EM $10 \mathrm{C} 100 \mathrm{kV}$, Germany) confirmed that the AgNPs existed on a nanoscale. In addition, this image showed that most of the particles were spherical with a size of $<40 \mathrm{~nm}$. Also, the AgNPs were acutely spread over the surface without agglomeration, and it is noticed from this image that they seem to be in a satisfying situation, while covered by the residual biomolecules of the aniseed extracts.

The high magnification FESEM image of AgNPs achieved by the FESEM machine (TESCAN, MIRA 3), as demonstrated in figure 6, displays the spherical shape of the biosynthesized AgNPs, which had a mean particle size diameter in the range of 20 to $50 \mathrm{~nm}$; that seems to correspond to the particle size illustrated in the TEM image. As is represented in figure 6 (inset), the EDX test result revealed a sharp signal in the Ag area while affirming that the AgNPs have formed. Due to SPR, normally AgNPs display a characteristic absorption peak at $\sim 3 \mathrm{keV}$ [39]. The EDX spectrum showed a strong absorption peak for silver, along with a weak oxygen peak that may have been derived from the extract (Biomolecules) bound towards the surface of the AgNPs, indicative of the reduction of $\mathrm{Ag}^{+}$to elemental $\mathrm{Ag}$. The other peak that corresponds to the presence of $\mathrm{Au}$ in the EDX is an artefact of the gold coating on the sample. In this spectrum, there were no extra peaks observed for silver compounds due to the complete reduction of silver ions and/or compounds to AgNPs [40].

\subsection{Antibacterial evaluation}

The analysis of the biosynthesized AgNPs regarding their antibacterial properties against common pathogenic bacteria (i.e., Escherichia coli and Pseudomonas aeruginosa; Gram negative and Staphylococcus aureus and Bacillus subtilis; Gram positive) was performed through the utilization of the well diffusion method, as has been previously reported $[41,42]$. Table 1 displays the zone of inhibition that existed on every side of the well, while it has been mentioned that the synthesized AgNPs can cause a notable effect on the growth prevention of bacteria. We did not detect any inhibition zone in the control group (shoot extract), which is a solution without AgNPs. As the volume of the stock solution has been escalated from 50 to $200 \mu \mathrm{l}$, the antibacterial effects of AgNPs moderately increase as well. These particular activities are commonly related to a number of mechanisms involving (a) the formation of reactive oxygen species such as $\left(\mathrm{O}^{2-}\right)$ and $\left(\mathrm{OH}^{\bullet}\right)$, (b) the existence of silver cations in AgNPs that create a bond on the side of sulphydryl groups that are directed to protein denaturation in bacteria, and (c) $\mathrm{Ag}^{+}$release from the AgNPs that merely penetrate to the cell and produce a drastic scratch to the bacteria, as is illustrated in figure 7. Metal depletion may be responsible for the formation of asymmetrically shaped pits in the external membrane and thereby changes

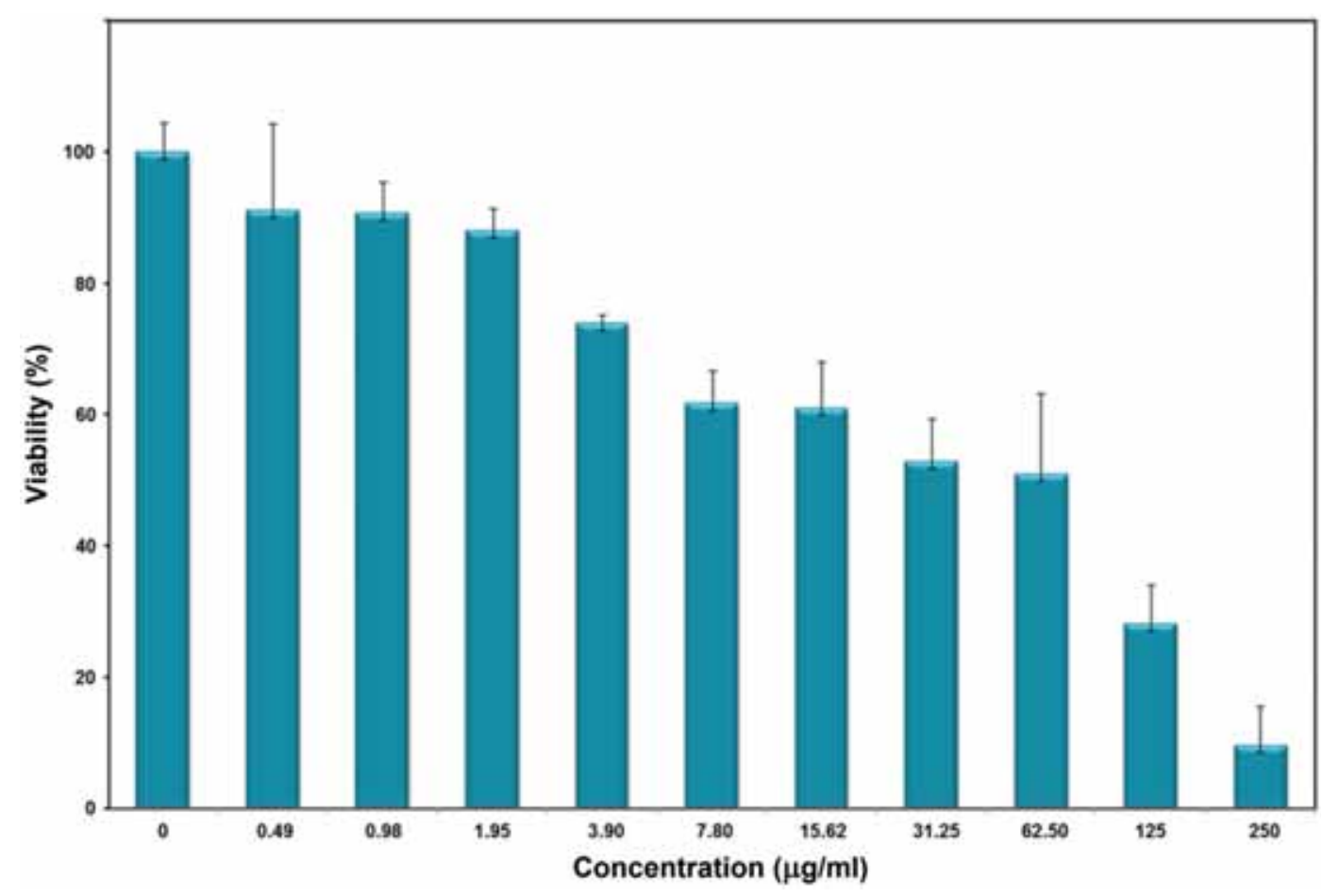

Figure 8. The cytotoxicity assay of the biosynthesized AgNPs in the Handelia trichophylla shoot extract. 
membrane penetrability [43]. The AgNPs are also capable of preventing the bacterial growth due to their small size and huge surface area which provide enough contact with the bacteria [44].

\subsection{Cytotoxicity effect}

The in vitro cytotoxicity properties of the biosynthesized AgNPs were observed against a cancerous cell line (murine Neuro2A neuroblastoma) via utilizing the MTT assay. The MTT assay results indicated a dose-dependent reduction in the viability percentage of Neuro2A cells after 24 h. Figure 8 indicates that the biosynthesized AgNPs seemed to be quite sensitive. The cellular toxicity effects of AgNPs are probably the outcome of the effective interaction of $\mathrm{Ag}$ atoms with the different bio-functional groups of present proteins (intracellular) [45].

Nonetheless, this project is the very first research on the employment of the Neuro2A neuroblastoma cell line against plant mediated AgNPs. This paper will improve the existing information about the potential advantages of colloidal AgNPs in Handelia trichophylla regarding the treatment of cancer. Nevertheless, it is required that the mechanisms of AgNP activities on cytotoxicity would be further investigated in order to evaluate the risks and advantages of the mentioned plant-based nanoparticles (the data used for analysing the cytotoxicity effects are reported as the mean \pm SD of the triplicates).

\section{Conclusions}

We have proposed a novel approach in this study regarding the biosynthesis of AgNPs from aqueous shoot extract of Handelia trichophylla. As was observed in the TEM/FESEM and UV-Vis/EDX analyses, the biosynthesized particles were formed in a spherical shape and had a size that ranged around 20-50 nm. This research study also discovered that these particular nanoparticles show antibacterial activities against a wide spectrum of human pathogenic bacteria. Therefore, as a conclusion, it could be assumed that the biosynthesis of AgNPs in plant extracts and through the use of the Handelia trichophylla shoot extract can stand as a 'green', cost-effective, facile and eco-friendly method that excludes the hazards that may rise out of utilizing harmful reducing and/or capping agents. Furthermore, this process has the potential of scaling up for industrial applications to widen the yield of nanoparticles significantly, which doubtlessly would begin its commercial viability in medicine.

\section{Acknowledgements}

The authors gratefully acknowledge the technical and financial support for this work which was provided by Mashhad University of Medical Sciences (Grant \# 941714).

\section{References}

[1] Zamiri R, Zakaria A, Ahangar H A, Darroudi M, Zamiri G, Rizwan Z et al 2013 Int. J. Nanomed. 8233

[2] Darroudi M, Ahmad M B, Zamiri R, Zak A K, Abdullah A H and Ibrahim N A 2011 Int. J. Nanomed. 6677

[3] Darroudi M, Ahmad M B, Zamiri R, Abdullah A H, Ibrahim N A and Sadrolhosseini A R 2011 Solid State Sci. 13520

[4] Makvandi P, Nikfarjam N, Sanjani N S and Qazvini N T 2015 Bull. Mater. Sci. 381625

[5] Yazdi M E T, Modarres M, Amiri M S and Darroudi M 2018 Res. Chem. Int. 44325

[6] Yazdi M E T, Khara J, Housaindokht M, Sadeghnia H R, Bahabadi S E, Amiri M S et al 2019 IET Nanobiotechnol. 13189

[7] Gould I R, Lenhard J R, Muenter A A, Godleski S A and Farid S 2000 J. Am. Chem. Soc. 12211934

[8] Joseph S and Mathew B 2015 Bull. Mater. Sci. 38659

[9] Pahlavan Noghabi M, Parizadeh M R, Ghayour-Mobarhan M, Taherzadeh D, Hosseini H A and Darroudi M $2017 \mathrm{~J}$. Mol. Struct. 1146499

[10] Raza Z A, Rehman A, Anwar F and Usman A 2016 Bull. Mater. Sci. 39391

[11] Khatami M, Pourseyedi S, Khatami M, Hamidi H, Zaeifi M and Soltani L 2015 Bioresour. Bioprocess 219

[12] Khorshidi A and Mardazad N 2016 Res. Chem. Intermed. 42 7551

[13] Maráková N, Humpolíček P, Kašpárková V, Capáková Z, Martinková L, Bober P et al 2017 Appl. Surf. Sci. 396169

[14] Stojkovska J, Djurdjevic Z, Jancic I, Bufan B, Milenkovic M, Jankovic R et al 2018 J. Biomater. Appl. 321197

[15] Darroudi M, Ahmad M B, Abdullah A H and Ibrahim N A 2011 Int. J. Nanomed. 6569

[16] Darroudi M, Zak A K, Muhamad M R, Huang N M and Hakimi M 2012 Mater. Lett. 66117

[17] Darroudi M, Ahmad M B, Zak A K, Zamiri R and Hakimi M 2011 Int. J. Mol. Sci. 126346

[18] Nadagouda M N, Speth T F and Varma R S 2011 Acc. Chem. Res. 44469

[19] Darroudi M, Ahmad M B, Hakimi M, Zamiri R, Zak A K, Hosseini H A et al 2013 Int. J. Miner. Metall. Mater. 20403

[20] Zamiri R, Zakaria A, Abbastabar H, Darroudi M, Husin M S and Mahdi M A 2011 Int. J. Nanomed. 6565

[21] Miri A, Sarani M, Bazaz M R and Darroudi M 2015 Spectrochim. Acta. A Mol. Biomol. Spectrosc. 141287

[22] Yazdi M E T, Khara J, Sadeghnia H R, Bahabadi S E and Darroudi M 2018 Res. Chem. Intermed. 441325

[23] Khatami M, Mortazavi S M, Kishani-Farahani Z, Amini A, Amini E and Heli H 2017 Iran J. Biotechnol. 1595

[24] Mortazavi S M, Khatami M, Sharifi I, Heli H, Kaykavousi K, Sobhani Poor M H et al 2017 J. Clust. Sci. 282997

[25] Khatami M, Alijani H, Sharifi I, Sharifi F, Pourseyedi S, Kharazi S et al 2017 Sci. Pharm. 8536

[26] Modarres M, Bahabadi S E and Yazdi M E T 2018 Cytotechnology 70741

[27] Vinmathi V and Jacob S J P 2015 Bull. Mater. Sci. 38625

[28] Yazdi M E T, Khara J, Husaindokht M R, Reza H, Sadeghnia S E B, Amiri M S et al 2018 Int. J. Basic Sci. Med. 399

[29] Amiri M S and Joharchi M R 2010 Iran J. Botany 32 246 
[30] Amiri M S, Jabbarzadeh P and Akhondi M 2012 J. Med. Plants Res. 6749

[31] Dovi K, Yoel K, Eugene R, Micha I, Ilan I and Yossi L 2001 Aquat. Microb. Ecol. 249

[32] Ahamed M, Khan M M, Siddiqui M, AlSalhi M S and Alrokayan S A 2011 Phys. E(Amsterdam, Netherland) 431266

[33] Krishnaraj C, Jagan E, Rajasekar S, Selvakumar P, Kalaichelvan P and Mohan N 2010 Colloids Surf. B 7650

[34] de Matos R A, da Silva Cordeiro T, Samad R E, Vieira N D and Courrol L C 2011 Colloids Surf. A Physicochem. Eng. Aspects $\mathbf{3 8 9} 134$

[35] Vidhu V, Aromal S A and Philip D 2011 Spectrochim. Acta A Mol. Biomol. Spectrosc. 83392

[36] Rajkumar P, Ravichandran K, Baneto M, Ravidhas C, Sakthivel B and Dineshbabu N 2015 Mater. Sci. Semicond. Process 35 189

[37] Niraimathi K L, Sudha V, Lavanya R and Brindha P 2013 Colloids Surf. B Biointerfaces 102288
[38] Prakash P, Gnanaprakasam P, Emmanuel R, Arokiyaraj S and Saravanan M 2013 Colloids Surf. B Biointerfaces 108 255

[39] Kaviya S, Santhanalakshmi J, Viswanathan B, Muthumary J and Srinivasan K 2011 Spectrochim. Acta A Mol. Biomol. Spectrosc. 79594

[40] Jyoti K, Baunthiyal M and Singh A 2016 Radiat. Res. Appl. Sci. 9217

[41] Verma V C, Kharwar R N and Gange A C 2009 Nanomedicine 5 33

[42] Wang W, Xiao K, He T and Zhu L 2015 J. Alloys Compd. 647 1007

[43] Rajeshkumar S and Bharath L 2017 Chem. Biol. Interact. 273 219

[44] Kanmani P and Rhim J-W 2014 Food Chem. 148 162

[45] Moaddab S, Ahari H, Shahbazzadeh D, Motallebi A A, Anvar A A, Rahman-Nya J et al 2011 Int. Nano Lett. 111 